\title{
Effect of Adhesive Joint End Shapes on the Ultimate Load-Bearing Capacity of Carbon Fibre-Reinforced Polymer/Steel Bonded Joints
}

\author{
Maciej Kowal' \\ 1 Department of Roads and Bridges, Faculty of Civil Engineering and Architecture, Lublin University of Technology, \\ Nadbystrzycka 40, 20-618 Lublin, Poland \\ e-mail:m.kowal@pollub.pl
}

\begin{abstract}
This paper reports the experimental results of a study investigating the effect of adhesive joint end shapes on the load-bearing capacity of carbon fibre-reinforce polymer (CFRP) and steel bonded joints. In the study, samples with new proprietary types of CFRP strip ends were examined. All samples were subjected to tensile quasi-static loading with a load rate of $1.5 \mathrm{~mm} / \mathrm{min}$. A total of 60 samples with CFRP/steel single overlap joints were tested to determine their ultimate load-bearing capacity, effective bond length and failure modes for the above variables. 8 joint end shapes of normal CFRP modulus with three lengths of CFRP overlap and one CFRP cross section (20 $\mathrm{x}$ $1.4 \mathrm{~mm}$ ) were used in this study. Laboratory test results showed that joint end shape has visible effect on the load capacity of the CFRP/steel bonded joints. The load-bearing capacity of the samples with a regular joint end was up to $28 \%$ lower than that of the samples with a plan-shaped end and $30 \%$ lower than that of the samples with a chamfered end with adhesive outflow. The differences in the results decreased with increase in joint end length towards the effective end length.
\end{abstract}

Keywords: steel, carbon fibre-reinforced polymer, overlap joint, bond end shape, load capacity, composite, adhesive joint.

\section{INTRODUCTION}

Steel bridges and other steel structures may pose problems with regard to their maintenance and operation. Most problems are associated with progressive corrosion and damage during their service life, as discussed by Kowal and Szala in [1]. Moreover, in the case of bridges, corrosion often requires restoring or increasing the load-bearing capacity of individual structural members or the entire structure. Usually, the reduction in capacity applies only to specific structural elements. First of all, in line with good engineering practice, repair of individual structural elements is considered. The replacement of a number of structural elements or the entire structure with a completely new construction are considered next. According to Bień [2], about $45 \%$ of railway bridge structures in Poland are over 100 years old, and only about $15 \%$ of these structures are under 40 years old. With such technical condition of the facilities, the construction of new structures may become inevitable. What is more, investors with financing options look for optimal solutions, which may determine the choice of more expensive options.

Conventional methods for strengthening steel structures are passive and active. The passive ones consist of removing a damaged or non-compliant existing element. Then, a new one element increasing the steel profile cross-section with the use of welded, bolted or frictional connections is inserted [3]. The active methods include external compression or static scheme change. The use of conventional methods may be difficult to implement or ineffective in economic or even technical terms.

The use of CFRP (carbon fibre reinforced polymer) composite materials has become a very promising alternative to passive methods for strengthening steel structures. CFRP fibers are corrosion resistant, have low weight and high tensile strength. The technique of adhesive bonding for composite elements offers many advantages such 
as easy application and increased fatigue resistance, which is crucial in the case of urgent repair works. CFRP composites appear to be a suitable material for structural repair. the use of CFRP for temporary repairs makes it possible to produce an optimal final solution. As discussed by Rudawska et al. [4], the strength of adhesive bonds may be similar to the strength of welded joints.

Positive effects of composite application also include increased load-bearing capacity of steel elements and bridges. Examples of the application of FRP tapes to strengthen steel bridges can be found all over the world, among others in the United States, as discussed by Charles [4] and Phares et al. [6], or in the UK, as shown by Moy [6] and Harries [8]. In Poland, the bridge over the Vistula River in Chełmno was strengthened, as described by Łagoda [9].

Potential failure modes_of reinforced elements and joint design procedures were discussed, among others, by Zhao and Zhang [10]. They presented a state-of-the-art review on the reinforcement of steel structures with composite materials. They covered the basics of designing the joint between FRP and steel elements.

The influence of composite sample end on the stresses in veneer was investigated, among others, by Stratford and Chen [11].

Currently, several methods are used to limit stresses in the joint and increase its load capacity. The first method is to change the type of adhesive to a more durable one. This is difficult to perform in-situ due to high requirements for steel surface preparation in terms of peel strength.

Another way to increase the load capacity of a joint is to modify the geometry of tape and/ or adhesive. This method also has its limitations which -in terms of the construction site - are associated with the necessity of fitting elements several times, as discussed by Stratford and Chen [11], Kowal [12], Linghoff et al. [13], Cadei et al. [14], Lang and Mallick [15], Kowal and Łagoda [16], Kowal and Hypki [17]. Belingardi et al. [18] showed that the maximum shear and failure stresses in a single lap joint decrease with increase in the angle of excess adhesive and that the best results can be achieved for the $45^{\circ}$ angle. The problem of joint end shape impact was also discussed by Hagani et al. [19].

The third method for reducing stresses in veneer and thus increasing joint load capacity is the use of adhesives with different shear modulus of the veneer, i.e. mixed adhesive joints. Mixed adhesive joints were discussed by Silva and Lopes [20], Fitton and Broughton [21], Silva and Adams [22, 23]. According to these authors, the use of adhesives with different modulus has several advantages, including the ease of implementation, higher joint strength compared to that of the joints made with the use of only one type of brittle adhesive, as discussed by Silva and Lopes [20]. The main disadvantage of using different types of adhesives in the joint is the difficulty of applying this solution in real construction conditions.

This study investigates the effects of joint end shapes and overlap lengths in carbon fibre reinforced polymer/steel bonded joints on the loadbearing capacity of these overlap joints under quasi-static loading conditions .

\section{MATERIALS AND METHODS}

\section{Materials}

Steel paddle-shaped flat bars with transverse notches and with a thickness of $8 \mathrm{~mm}$ were tested,

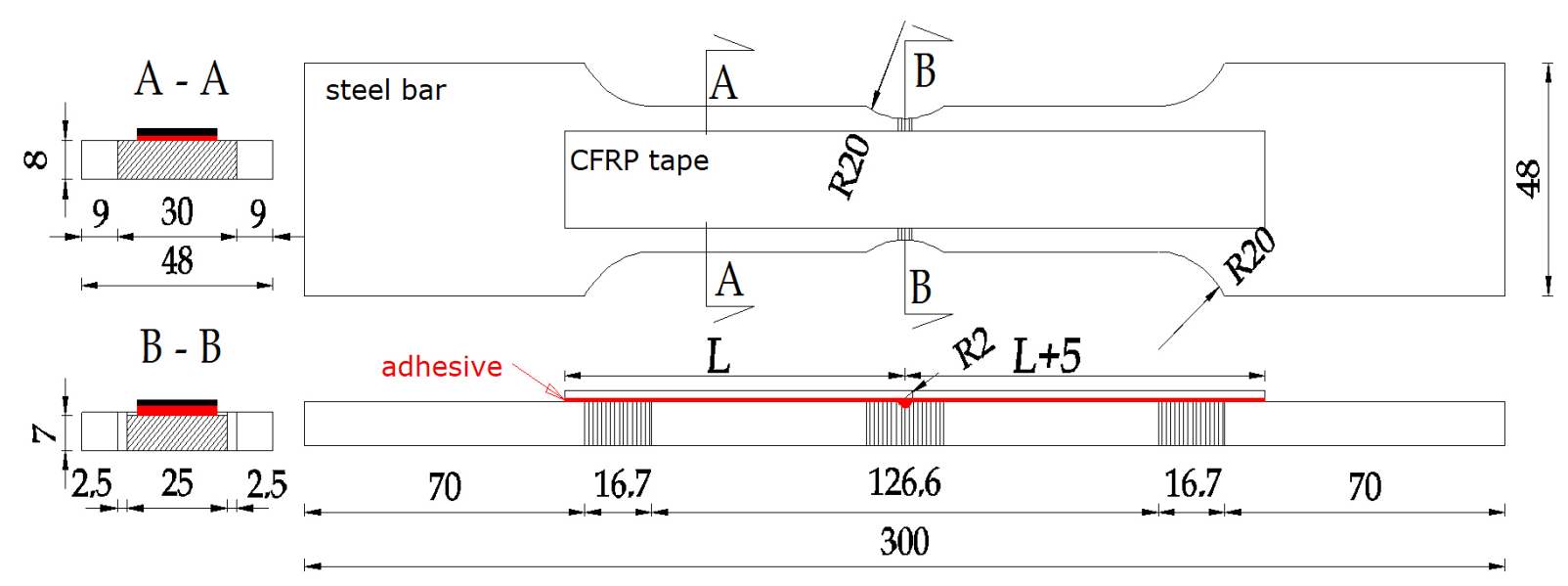

Fig. 1. Schematic design of the test sample 
Table 1. Parameters of the samples with an overlap length of $80.0 \mathrm{~mm}$

\begin{tabular}{|c|c|c|c|c|c|c|}
\hline $\begin{array}{c}\text { Sample } \\
\text { number }\end{array}$ & $\begin{array}{c}\text { Average steel } \\
\text { thickness [mm] }\end{array}$ & $\begin{array}{c}\text { Steel thickness in } \\
\text { the notch [mm] }\end{array}$ & $\begin{array}{c}\text { Steel width in } \\
\text { the notch [mm] }\end{array}$ & $\begin{array}{c}\text { Average sample } \\
\text { thickness [mm] }\end{array}$ & $\begin{array}{c}\text { Average adhesive } \\
\text { thickness [mm] }\end{array}$ & $\begin{array}{c}\text { Adhesive thickness } \\
\text { in the notch [mm] }\end{array}$ \\
\hline Z.1 & 8.03 & 6.90 & 24.90 & 10.31 & 0.88 & 1.96 \\
\hline Z.2 & 8.16 & 6.98 & 24.88 & 10.49 & 0.93 & 2.10 \\
\hline Z.3 & 8.00 & 6.98 & 24.88 & 10.61 & 1.21 & 2.22 \\
\hline F.1 & 8.02 & 6.74 & 24.90 & 10.61 & 1.19 & 2.46 \\
\hline F.2 & 8.08 & 6.76 & 24.96 & 10.53 & 1.05 & 2.26 \\
\hline F.3 & 8.02 & 6.74 & 24.98 & 10.42 & 1.00 & 2.28 \\
\hline 50.1 & 8.13 & 6.70 & 24.88 & 10.41 & 0.88 & 2.30 \\
\hline 50.2 & 8.00 & 6.92 & 24.88 & 10.60 & 1.20 & 2.26 \\
\hline 50.3 & 8.02 & 6.65 & 24.90 & 10.38 & 0.96 & 2.33 \\
\hline 42.1 & 8.03 & 6.60 & 24.96 & 10.42 & 0.99 & 2.36 \\
\hline 42.2 & 8.12 & 6.80 & 24.84 & 10.62 & 1.10 & 2.40 \\
\hline 42.3 & 7.99 & 6.74 & 24.90 & 10.50 & 1.11 & 2.34 \\
\hline 42.3 .1 & 8.07 & 6.70 & 25.04 & 10.53 & 1.06 & 2.42 \\
\hline 42.3 .2 & 8.10 & 6.90 & 25.00 & 10.42 & 0.92 & 2.12 \\
\hline 42.3 .3 & 8.03 & 6.92 & 24.90 & 10.45 & 1.02 & 2.18 \\
\hline 42.4 .1 & 8.09 & 6.76 & 24.88 & 10.45 & 0.96 & 2.34 \\
\hline 42.4 .2 & 8.03 & 6.68 & 24.92 & 10.63 & 1.20 & 2.54 \\
\hline 42.4 .3 & 8.09 & 7.00 & 24.90 & 10.43 & 0.94 & 2.02 \\
\hline 42.5 .1 & 8.06 & 6.70 & 24.86 & 10.46 & 1.00 & 2.34 \\
\hline 42.5 .2 & 8.04 & 6.70 & 24.92 & 10.39 & 0.95 & 2.28 \\
\hline 42.5 .3 & 8.07 & 6.98 & 24.88 & 10.41 & 0.94 & 2.02 \\
\hline
\end{tabular}

Table 2. Parameters of the samples with an overlap length of $82.5 \mathrm{~mm}$

\begin{tabular}{|c|c|c|c|c|c|c|}
\hline $\begin{array}{c}\text { Sample } \\
\text { number }\end{array}$ & $\begin{array}{c}\text { Average steel } \\
\text { thickness [mm] }\end{array}$ & $\begin{array}{c}\text { Steel thickness in } \\
\text { the notch [mm] }\end{array}$ & $\begin{array}{c}\text { Steel width in } \\
\text { the notch [mm] }\end{array}$ & $\begin{array}{c}\text { Average sample } \\
\text { thickness [mm] }\end{array}$ & $\begin{array}{c}\text { Average adhesive } \\
\text { thickness [mm] }\end{array}$ & $\begin{array}{c}\text { Adhesive thickness } \\
\text { in the notch [mm] }\end{array}$ \\
\hline 50.1 & 8.16 & 6.60 & 25.06 & 10.48 & 0.92 & 2.36 \\
\hline 50.2 & 8.10 & 7.10 & 25.00 & 10.63 & 1.13 & 2.10 \\
\hline 50.3 & 8.13 & 6.60 & 25.10 & 10.71 & 1.18 & 2.64 \\
\hline 50.3 .1 & 8.07 & 6.70 & 25.08 & 10.64 & 1.17 & 2.62 \\
\hline 50.3 .2 & 8.10 & 7.00 & 25.02 & 10.83 & 1.33 & 2.36 \\
\hline 50.3 .3 & 8.11 & 7.10 & 25.00 & 10.45 & 0.94 & 1.96 \\
\hline 42.1 & 8.11 & 7.04 & 25.04 & 10.49 & 0.98 & 1.86 \\
\hline 42.2 & 8.30 & 6.70 & 25.06 & 10.72 & 1.02 & 2.62 \\
\hline 42.3 & 8.11 & 7.32 & 25.06 & 10.54 & 1.03 & 1.59 \\
\hline 42.3 .1 & 8.09 & 6.76 & 25.04 & 10.75 & 1.26 & 2.54 \\
\hline 42.3 .2 & 8.08 & 6.60 & 24.90 & 10.38 & 0.90 & 2.26 \\
\hline 42.3 .3 & 8.20 & 6.80 & 24.98 & 10.65 & 1.05 & 2.44 \\
\hline 42.4 .1 & 8.18 & 6.70 & 24.98 & 10.61 & 1.03 & 2.60 \\
\hline 42.4 .2 & 8.17 & 6.94 & 24.94 & 10.81 & 1.24 & 2.44 \\
\hline 42.4 .3 & 8.03 & 7.16 & 25.00 & 10.47 & 1.04 & 1.72 \\
\hline 42.5 .1 & 8.11 & 6.62 & 24.90 & 10.77 & 1.26 & 2.78 \\
\hline 42.5 .2 & 8.07 & 6.62 & 25.06 & 10.85 & 1.38 & 2.72 \\
\hline 42.5 .3 & 8.11 & 7.20 & 24.94 & 10.56 & 1.05 & 1.76 \\
\hline
\end{tabular}

see Figure 1. Since this study focuses on the properties of steel/CFRP bonded joints, mild S235JR+AR grade steel plates were used. Mechanical properties of the steel bars were tested under quasi-static loading. The measured yield and ultimate tensile stresses were $308.0 \mathrm{MPa}$ and $432.0 \mathrm{MPa}$, respectively. 
Table 3. Parameters of the samples with an overlap length of $85.0 \mathrm{~mm}$

\begin{tabular}{|c|c|c|c|c|c|c|}
\hline $\begin{array}{c}\text { Sample } \\
\text { number }\end{array}$ & $\begin{array}{c}\text { Average steel } \\
\text { thickness [mm] }\end{array}$ & $\begin{array}{c}\text { Steel thickness in } \\
\text { the notch [mm] }\end{array}$ & $\begin{array}{c}\text { Steel width in } \\
\text { the notch [mm] }\end{array}$ & $\begin{array}{c}\text { Average sample } \\
\text { thickness [mm] }\end{array}$ & $\begin{array}{c}\text { Average adhesive } \\
\text { thickness [mm] }\end{array}$ & $\begin{array}{c}\text { Adhesive thickness } \\
\text { in the notch [mm] }\end{array}$ \\
\hline Z.1 & 8.16 & 7.20 & 25.02 & 10.49 & 0.93 & 1.90 \\
\hline Z.2 & 8.10 & 7.12 & 25.08 & 10.65 & 1.15 & 2.14 \\
\hline Z.3 & 8.17 & 7.16 & 25.06 & 10.36 & 0.79 & 1.80 \\
\hline F.1 & 8.18 & 6.72 & 25.06 & 10.40 & 0.82 & 2.28 \\
\hline F.2 & 8.16 & 7.18 & 25.08 & 10.71 & 1.15 & 2.04 \\
\hline F.3 & 8.20 & 6.92 & 25.08 & 10.58 & 0.98 & 2.38 \\
\hline 50.1 & 8.17 & 7.20 & 25.08 & 10.49 & 0.92 & 1.78 \\
\hline 50.2 & 8.16 & 7.30 & 25.00 & 10.35 & 0.79 & 1.76 \\
\hline 50.3 & 8.11 & 7.16 & 25.08 & 10.56 & 1.05 & 1.94 \\
\hline 42.1 & 8.21 & 7.18 & 25.06 & 10.65 & 1.04 & 2.18 \\
\hline 42.2 & 8.15 & 7.14 & 25.06 & 10.51 & 0.96 & 1.86 \\
\hline 42.3 & 8.17 & 7.16 & 24.90 & 10.69 & 1.12 & 2.10 \\
\hline 42.3 .1 & 8.12 & 7.20 & 25.02 & 10.87 & 1.35 & 2.24 \\
\hline 42.3 .2 & 8.19 & 7.16 & 25.06 & 10.63 & 1.04 & 2.08 \\
\hline 42.3 .3 & 8.16 & 7.26 & 25.00 & 10.33 & 0.77 & 2.02 \\
\hline 42.4 .1 & 8.18 & 7.40 & 25.18 & 10.68 & 1.10 & 2.00 \\
\hline 42.4 .2 & 8.12 & 7.10 & 25.00 & 10.49 & 0.97 & 1.84 \\
\hline 42.4 .3 & 8.15 & 7.30 & 25.08 & 10.51 & 0.96 & 1.92 \\
\hline 42.5 .1 & 8.19 & 7.18 & 24.90 & 10.73 & 1.14 & 2.12 \\
\hline 42.5 .2 & 8.28 & 7.30 & 25.02 & 10.41 & 0.73 & 1.64 \\
\hline 42.5 .3 & 8.11 & 7.20 & 24.92 & 10.64 & 13 & 1.96 \\
\hline
\end{tabular}

In this study, one type of CFRP tapes were used to investigate joint behavior. They were S\&P CFK-Lamellen 200/2000 composite tapes based on epoxy resins with carbon fibers. The tapes had a width of $20 \mathrm{~mm}$ and a thickness of $1.4 \mathrm{~mm}$. Their ultimate tensile strength, ultimate strain and elastic modulus were as follows: $2500 \mathrm{MPa}, 1.25 \%$ and $210.0 \mathrm{GPa}$, respectively, according to the manufacturer's data.

The S\&P Resin 220 adhesive used for sample preparation is a two-part epoxy. Properties of the adhesive were assumed to be in accordance with the technical data sheet of the product, i.e. elastic modulus $>7.1 \mathrm{GPa}$, tensile strength $11.4 \mathrm{Mpa}$, shear strength $\geq 26.0 \mathrm{MPa}$, peel strength of the S\&P Lamellen tape $\geq 3.0 \mathrm{Mpa}$, and peel strength on steel on steel $\geq 14.0 \mathrm{MPa}$.

Specifications of the samples are given in Tables 1-3.

\section{Sample preparation}

To ensure optimal contact between the epoxy and the steel plate along the bond area, the steel surface was sandblasted. To provide a chemically active surface, the sandblasted surface was cleaned with acetone before adhesive application. The S\&P Resin 220 adhesive consists of two parts. The mixing procedure $(80 \%$ comp. A: $20 \%$ comp. B) was performed in compliance with the manufacturer's specifications. The CFRP tapes were pre-cut to the required length with small allowance. After that, the ends of the strips were milled to the required end shape and the expected length using a CNC milling machine. To ensure that the CFRP tapes were free from any dust and greasy dirt, they were wiped with acetone. Next, the CFRP samples were attached to the sandblasted steel surface using the S\&P Resin 220 epoxy. The CFRP strips were pressed against a flat steel mould so that excess adhesive could flow out from under them and that the total thickness of the CFRP strips and adhesive would remain constant over the entire length of the strips. The adhesive excess was removed or shaped with a spatula depending on the sample type.

The bond length $L$ (Figure 1) on one side of the joint was $5 \mathrm{~mm}$ shorter than on the other side $(L+5)$ to ensure that failure would occur on the shorter side $(L)$. The sample preparation and storage temperature was $22-24^{\circ} \mathrm{C}$. The samples were made in batches of 3 pieces ( 20 lots of samples). 

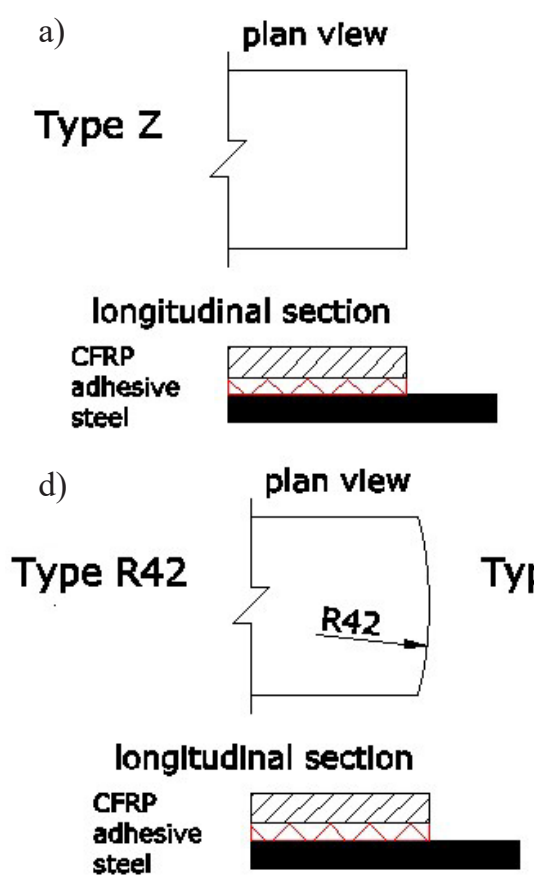

b)

Type F

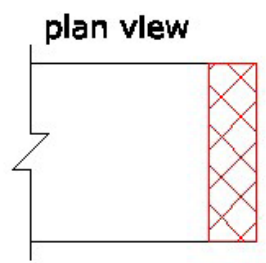

longitudinal section

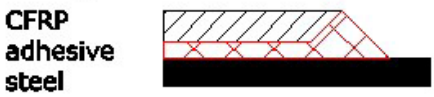

e)

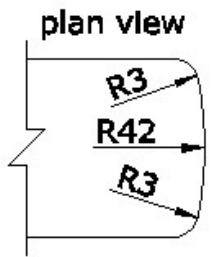

longltudinal sectlon

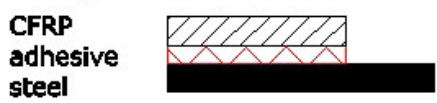

c)

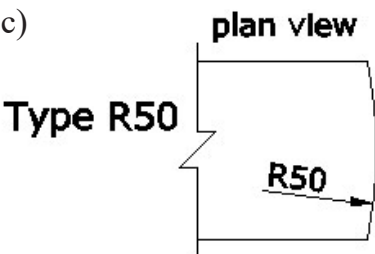

longitudinal section

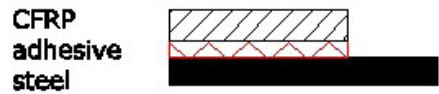

f)

plan view

Fig. 2. Schematic of strip end shapes

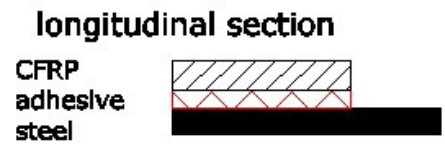

In this study, 60 reinforced (20 configurations of adhesive joint ends, with 3 samples in each configuration) and 3 non-reinforced steel reference samples were prepared and subjected to axial tension. Each reinforced sample consisted of a steel flat bar reinforced on one side with epoxy resin overlap made of CFRP strips with three different overlap lengths $L=80 ; 82.5$; $85 \mathrm{~mm}$. The samples were made in six shapes of strip end. A schematic of the strip end shape is shown in Figure 2.

\section{Test procedure}

Experiments were conducted with a servohydraulic testing machine, MTS 319.25, The machine has a maximum capacity of $250 \mathrm{kN}$ in tension and is provided with hydraulic grips. The single lap joint samples were tested under static tensile loads. Tensile loading was applied with a loading rate of $1.5 \mathrm{~mm} / \mathrm{min}$. Piston force and displacement were measured with a frequency of $20 \mathrm{~Hz}$.

As mentioned previously, 20 types of reinforced samples, and 3 steel reference samples were used in the static tests, each having the same CFRP cross-sectional area and the same modulus of elasticity yet three different overlap lengths and 8 different joint end shapes. A total of 60 samples with CFRP/steel single overlap joints using S\&P Resin 220 epoxy were tested to determine their ultimate load-bearing capacity $F_{D}$, effective bond length $L_{e f f}$ and failure modes for the above parameters.

Three different series of sample types (80; $82.5 ; 85)$ were examined in this testing program. The differences between these types are related to overlap length and joint end shape. The measured adhesive thickness of all samples was similar. All samples were tested in the same environment and had the same curing time.

Total thickness was measured using an electronic caliper. Thickness was measured at both ends and in the middle of the strips. The total joint thickness was taken as the average of three measurements. By knowing the thickness of the entire sample, CFRP laminate (measured before adhesive bonding) and steel plate (measured after sandblasting), adhesive thickness could be calculated.

\section{RESULTS AND DISCUSSION}

\section{Laboratory test results}

An analysis of the laboratory results for all samples reveals discrepancies in the results of given systems (see Tables 4-6). It was assumed that the desired test result would be to obtain the coefficient of variation (COV, see Equation 1 , in a group of samples) to the average failure force $\left(\mathrm{F}_{\mathrm{D} \text {.av }}\right)$ ratio under $5 \%$. 


$$
\mathrm{COV}=\mathrm{SD} / \mathrm{F}_{\mathrm{Dav}}
$$

The second assumption was that the ratio of the square deviation of failure force to the square of the mean of this force (SDMS, see Equation 2) would be under $0.25 \%$.

$$
\mathrm{SDMS}=\left(\mathrm{F}_{\mathrm{Di}}-\mathrm{F}_{\mathrm{Dav}}\right)^{2} / \mathrm{F}_{\text {Dav }}{ }^{2}
$$

For a small sample population in the group (here, each group consisted of 3 samples), the expected low values of COV\% and SDMS indicate correct sample preparation and the expected reproducibility of results.

For 5 types of samples, the COV\% exceeded the assumed value of $5 \%$. This applied to the samples of types $80 . \mathrm{Z}(16.9 \%)$, 80.R50 (5.2\%), 80.R42.R5 (6.0\%), 85.Z (6.3\%), and 85.F $(11.5 \%)$. The assumed SDMS value $(\leq 0.25 \%)$ was exceeded in 10 out of 60 samples - 80.R50.1 (0,34\%); 80.R42R5.1 (0.26\%); 80.Z.1 (0.67\%); 80.Z.2 (3.78\%); 80.Z.3 (1.27\%); 825.R50.1 (0.27\%); 85F.1 (1,67\%); 85F.2 (0.80\%); 85.Z.2 $(0.33 \%)$; $85 . Z .3(0.46 \%)$. 8 of 10 samples that exceeded the assumed SDMS belonged to the population of types exceeding the assumed $\mathrm{COV} \%$ $(5 \%)$. While processing the tensile testing results by the statistical Dixon test, it was decided that all results had to be included.
Table 4 presents the results obtained for 21 samples with an overlap length of $80 \mathrm{~mm}$, as well as the values of failure forces $\left(F_{D}\right)$, mean values of failure forces $\left(\mathrm{F}_{\mathrm{Dav}}\right)$, failure forces with a probability of $95 \%\left(\mathrm{~F}_{95 \%}\right)$, standard deviation (SD), coefficient of variation (COV), and the SDMS ratio for each analysed population.

Table 5 presents the results obtained for 18 samples with an overlap length of $82.5 \mathrm{~mm}$, as well as the values of $\mathrm{F}_{\mathrm{D}}, \mathrm{F}_{\mathrm{Dav}}, \mathrm{F}_{95 \%}, \mathrm{SD}, \mathrm{COV}$, and SDMS for each analysed population. The samples with $82.5 \mathrm{~mm}$ overlap length were not reinforced with $\mathrm{Z}$ and F-type ends, but - additionally - a R50R3-type end was introduced.

Table 6 presents the results obtained for 21 samples with an overlap length of $85 \mathrm{~mm}$, as well as the values of $\mathrm{F}_{\mathrm{D}}, \mathrm{F}_{\mathrm{Dav}}, \mathrm{F}_{95 \%}, \mathrm{SD}, \mathrm{COV}$, and SDMS for each analysed population.

\section{Effect of overlap length}

Considering the results of failure force in relation to overlap length, the expected results were obtained for 5 out of 7 sample types for $\mathrm{F}_{95 \%}$ and $\mathrm{F}_{\text {Dav }}$.

For the samples with the $\mathrm{F}$ type bond ends (Fig. 2b), $\mathrm{F}_{\text {Dav }}$ and $\mathrm{F}_{95 \%}$ are higher for the overlap length of $80 \mathrm{~mm}$ than for that of $85 \mathrm{~mm}$.

\begin{tabular}{|c|c|c|c|c|c|c|}
\hline Sample number & $\mathrm{FD}[\mathrm{kN}]$ & $\mathrm{F}_{\mathrm{Dav}}[\mathrm{kN}]$ & $\mathrm{SD}[\mathrm{kN}]$ & COV [\%] & $\mathrm{F}_{95 \%}[\mathrm{kN}]$ & SDMS [\%] \\
\hline Z.1 & 56.414 & \multirow{3}{*}{61.43} & \multirow{3}{*}{10.386} & \multirow{3}{*}{16.91} & \multirow{3}{*}{44.29} & 0.6656 \\
\hline Z.2 & 73.367 & & & & & 3.7795 \\
\hline Z.3 & 54.495 & & & & & 1.2730 \\
\hline 42.1 & 57.126 & \multirow{3}{*}{55.21} & \multirow{3}{*}{1.991} & \multirow{3}{*}{3.61} & \multirow{3}{*}{51.93} & 0.1198 \\
\hline 42.2 & 53.153 & & & & & 0.1394 \\
\hline 42.3 & 55.365 & & & & & 0.0007 \\
\hline 50.1 & 60.300 & \multirow{3}{*}{56.96} & \multirow{3}{*}{2.955} & \multirow{3}{*}{5.19} & \multirow{3}{*}{52.09} & 0.3430 \\
\hline 50.2 & 55.916 & & & & & 0.0338 \\
\hline 50.3 & 54.676 & & & & & 0.1613 \\
\hline 42.5 .1 & 56.772 & \multirow{3}{*}{59.83} & \multirow{3}{*}{2.697} & \multirow{3}{*}{4.51} & \multirow{3}{*}{55.38} & 0.2614 \\
\hline 42.5 .2 & 60.854 & & & & & 0.0292 \\
\hline 42.5 .3 & 61.867 & & & & & 0.1158 \\
\hline 42.4 .1 & 60.663 & \multirow{3}{*}{60.15} & \multirow{3}{*}{2.436} & \multirow{3}{*}{4.05} & \multirow{3}{*}{56.13} & 0.0072 \\
\hline 42.4 .2 & 57.501 & & & & & 0.1942 \\
\hline 42.4 .3 & 62.292 & & & & & 0.1266 \\
\hline 42.3 .1 & 58.826 & \multirow{3}{*}{60.21} & \multirow{3}{*}{1.992} & \multirow{3}{*}{3.31} & \multirow{3}{*}{56.92} & 0.0528 \\
\hline 42.3 .2 & 62.492 & & & & & 0.1437 \\
\hline 42.3 .3 & 59.310 & & & & & 0.0223 \\
\hline F.1 & 59.960 & \multirow{3}{*}{61.34} & \multirow{3}{*}{2.145} & \multirow{3}{*}{3.50} & \multirow{3}{*}{57.80} & 0.0508 \\
\hline F.2 & 63.814 & & & & & 0.1623 \\
\hline F.3 & 60.255 & & & & & 0.0315 \\
\hline
\end{tabular}

Table 4. Results of $\mathrm{F}_{\mathrm{D}}, \mathrm{F}_{\mathrm{Dav}}, \mathrm{F}_{95 \%}, \mathrm{SD}, \mathrm{COV}$, SDMS for the samples with an overlap length of $\mathrm{L}=80.0 \mathrm{~mm}$ 
Table 5. Results of $\mathrm{F}_{\mathrm{D}}, \mathrm{F}_{\mathrm{Dav}}, \mathrm{F}_{95 \%}, \mathrm{SD}, \mathrm{COV}$, SDMS for the samples with an overlap length of $\mathrm{L}=82.5 \mathrm{~mm}$

\begin{tabular}{|c|c|c|c|c|c|c|}
\hline Sample number & $\mathrm{FD}[\mathrm{kN}]$ & $\mathrm{F}_{\mathrm{Dav}}[\mathrm{kN}]$ & $\mathrm{SD}[\mathrm{kN}]$ & COV [\%] & $\mathrm{F}_{95 \%}[\mathrm{kN}]$ & SDMS [\%] \\
\hline 42.1 & 57.148 & \multirow{3}{*}{55.22} & \multirow{3}{*}{2.001} & \multirow{3}{*}{3.62} & \multirow{3}{*}{51.92} & 0.1216 \\
\hline 42.2 & 53.153 & & & & & 0.1404 \\
\hline 42.3 & 55.365 & & & & & 0.0007 \\
\hline 50.1 & 63.096 & \multirow{3}{*}{59.95} & \multirow{3}{*}{2.951} & \multirow{3}{*}{4.92} & \multirow{3}{*}{55.08} & 0.2747 \\
\hline 50.2 & 57.241 & & & & & 0.2047 \\
\hline 50.3 & 59.524 & & & & & 0.0051 \\
\hline 42.4 .1 & 58.855 & \multirow{3}{*}{59.76} & \multirow{3}{*}{1.621} & \multirow{3}{*}{2.71} & \multirow{3}{*}{57.09} & 0.0229 \\
\hline 42.4 .2 & 61.631 & & & & & 0.0981 \\
\hline 42.4 .3 & 58.793 & & & & & 0.0262 \\
\hline 50.3 .1 & 59.058 & \multirow{3}{*}{60.01} & \multirow{3}{*}{1.479} & \multirow{3}{*}{2.46} & \multirow{3}{*}{57.57} & 0.0250 \\
\hline 50.3 .2 & 59.252 & & & & & 0.0158 \\
\hline 50.3 .3 & 61.711 & & & & & 0.0806 \\
\hline 42.5 .1 & 58.233 & \multirow{3}{*}{58.57} & \multirow{3}{*}{0.556} & \multirow{3}{*}{0.95} & \multirow{3}{*}{57.65} & 0.0032 \\
\hline 42.5 .2 & 58.255 & & & & & 0.0028 \\
\hline 42.5 .3 & 59.207 & & & & & 0.0120 \\
\hline 42.3 .1 & 61.031 & \multirow{3}{*}{61.56} & \multirow{3}{*}{2.131} & \multirow{3}{*}{3.46} & \multirow{3}{*}{58.04} & 0.0073 \\
\hline 42.3 .2 & 63.903 & & & & & 0.1451 \\
\hline 42.3 .3 & 59.740 & & & & & 0.0872 \\
\hline
\end{tabular}

Table 6. Results of $\mathrm{F}_{\mathrm{D}}, \mathrm{F}_{\text {Dav }}, \mathrm{F}_{95 \%}, \mathrm{SD}, \mathrm{COV}$, SDMS for the samples with an overlap length of $\mathrm{L}=85.0 \mathrm{~mm}$

\begin{tabular}{|c|c|c|c|c|c|c|}
\hline Sample number & $\mathrm{FD}[\mathrm{kN}]$ & $\mathrm{F}_{\mathrm{Dav}}[\mathrm{kN}]$ & $\mathrm{SD}[\mathrm{kN}]$ & COV [\%] & $\mathrm{F}_{95 \%}[\mathrm{kN}]$ & SDMS [\%] \\
\hline F.1 & 68.141 & \multirow{3}{*}{60.34} & \multirow{3}{*}{6.920} & \multirow{3}{*}{11.47} & \multirow{3}{*}{48.92} & 1.6701 \\
\hline F.2 & 54.935 & & & & & 0.8031 \\
\hline F.3 & 57.952 & & & & & 0.1570 \\
\hline Z.1 & 61.936 & \multirow{3}{*}{62.58} & \multirow{3}{*}{3.963} & \multirow{3}{*}{6.33} & \multirow{3}{*}{56.04} & 0.0107 \\
\hline Z.2 & 58.983 & & & & & 0.3309 \\
\hline Z.3 & 66.830 & & & & & 0.4605 \\
\hline 42.1 & 59.077 & \multirow{3}{*}{59.28} & \multirow{3}{*}{1.286} & \multirow{3}{*}{2.17} & \multirow{3}{*}{57.16} & 0.0012 \\
\hline 42.2 & 58.108 & & & & & 0.0391 \\
\hline 42.3 & 60.655 & & & & & 0.0538 \\
\hline 42.3 .1 & 57.911 & \multirow{3}{*}{57.98} & \multirow{3}{*}{0.063} & \multirow{3}{*}{0.11} & \multirow{3}{*}{57.88} & 0.0002 \\
\hline 42.3 .2 & 58.029 & & & & & 0.0001 \\
\hline 42.3 .3 & 58.007 & & & & & 0.0000 \\
\hline 42.5 .1 & 60.344 & \multirow{3}{*}{60.86} & \multirow{3}{*}{1.303} & \multirow{3}{*}{2.14} & \multirow{3}{*}{58.71} & 0.0071 \\
\hline 42.5 .2 & 62.336 & & & & & 0.0592 \\
\hline 42.5 .3 & 59.886 & & & & & 0.0254 \\
\hline 42.4 .1 & 60.093 & \multirow{3}{*}{59.79} & \multirow{3}{*}{0.638} & \multirow{3}{*}{1.07} & \multirow{3}{*}{58.74} & 0.0026 \\
\hline 42.4 .2 & 60.218 & & & & & 0.0051 \\
\hline 42.4 .3 & 59.056 & & & & & 0.0150 \\
\hline 50.1 & 63.298 & \multirow{3}{*}{62.24} & \multirow{3}{*}{1.063} & \multirow{3}{*}{1.71} & \multirow{3}{*}{60.48} & 0.0291 \\
\hline 50.2 & 62.239 & & & & & 0.0000 \\
\hline 50.3 & 61.173 & & & & & 0.0292 \\
\hline
\end{tabular}

For the R42R3 type samples (Fig. 2e) $\mathrm{F}_{\text {Dav }}$ is the highest for the overlap length of $82.5 \mathrm{~mm}$, and the lowest for the overlap length of $85 \mathrm{~mm}$. Regarding $\mathrm{F}_{95 \%}$, the failure force is the highest for the overlap length of $82.5 \mathrm{~mm}$ and the lowest for the $80 \mathrm{~mm}$ length. The difference in the failure force $\mathrm{F}_{95 \%}$ between the $82.5 \mathrm{~mm}$ and $85 \mathrm{~mm}$ overlap length samples amounts to $0.28 \%$ (with a measurement error of $1.7 \%$ ). The results can thus be considered identical. 
Regarding the R42-type bond ends, $\mathrm{F}_{95 \%}$ for the $\mathrm{L}=80 \mathrm{~mm}$ and $\mathrm{L}=82.5 \mathrm{~mm}$ differs by $0.02 \%$ in favour of the $80 \mathrm{~mm}$ overlap length sample (with a measurement error of $1.8 \%$ ). The results can be considered the same.

In the case of the R42R5 type samples, $F_{\text {Dav }}$ is the highest for the overlap length of $85 \mathrm{~mm}$ and the lowest for the overlap length of $82.5 \mathrm{~mm}$. The difference in the failure force between $\mathrm{L}=80 \mathrm{~mm}$ and $\mathrm{L}=82.5 \mathrm{~mm}$ amounts to $2.15 \%$ (with a measurement error of $1.7 \%$ ). The results of $\mathrm{F}_{\text {Dav }}$ and $\mathrm{F}_{95 \%}$ in relation to overlap length are listed in Table 7.

$$
\Delta F_{95 \% 1}=\left(F_{95 \% \_m a x}-F_{95 \% \_}\right) / F_{95 \% \_} i
$$

where: $\Delta \mathrm{F}_{95 \% 1}-$ difference in the load capacity $[\%]$.

$$
\Delta F_{\text {Dav1 }}=\left(F_{\text {Dav_max }}-F_{\text {Dav } i}\right) / F_{\text {Dav_ } i}
$$

where: $\Delta \mathrm{F}_{\text {Davl }}-$ difference in the mean load capacity.

\section{Effect of joint end shape}

The relationships between failure forces versus joint end types for the length groups of 80 , 82.5 and $85 \mathrm{~mm}$ are presented in Table 8 .

Considering the results of failure forces in relation to joint end shape, a detailed analysis of the results had to be performed. Based on previous research results $[10,11,13,16]$, the normal type end was expected to give the lowest results, while the other ends were expected to lead to increased joint load capacity. However, for the Ftype samples with a tapered end with adhesive outflow and an end length of $85 \mathrm{~mm}$, the failure force $\mathrm{F}_{95 \%}$ is the lowest in the group (14.5\% lower than that obtained for the sample with a normal type end). This result is inconsistent with the author's previous research results $[10,13]$. This finding disagrees with the results obtained for the $80 \mathrm{~mm}$ overlap length group, where the Z-type sample has the lowest load-bearing capacity. The F-type samples have a $30.5 \%$ higher $\mathrm{F}_{95 \%}$ compared to the Z-type samples. The author assumed that such unexpected results were due to improper sample preparation. Slight damage of the CFRP strip end when milling it to the 45 degree angle or unnoticed contamination of the steel surface in strip end area during the waiting process could be the cause. The author encountered similar problems when conducting research for his doctoral dissertation [12].

For the samples with the R42-type end, the joint load capacity $\mathrm{F}_{95 \%}$ is $2.3-7.2 \%$ higher than the $\mathrm{F}_{95 \%}$ of the normal type ends. As expected, the results show that the sample rounding leads to reduced stresses at the joint end.

As for the samples with the R50 type end, the joint load capacity $\mathrm{F}_{95 \%}$ is $7.6-17.6 \%$ higher than that of the normal type end and $0.3-6.8 \%$ higher

\begin{tabular}{|c|c|c|c|c|c|c|c|}
\hline $\mathrm{L}[\mathrm{mm}]$ & Sample type & $\mathrm{F}_{95 \%}[\mathrm{kN}]$ & $\Delta \mathrm{F}_{95 \% 1}[]$ & $\mathrm{L}[\mathrm{mm}]$ & Sample type & $\mathrm{F}_{\mathrm{Dav}}[\mathrm{kN}]$ & $\Delta \mathrm{F}_{\text {Dav1 }}[\%]$ \\
\hline 85.0 & \multirow[t]{2}{*}{ Z } & 56.04 & \multirow{3}{*}{-20.97} & 85.0 & \multirow[t]{2}{*}{ Z } & 62.58 & \\
\hline 80.0 & & 44.29 & & 80.0 & & 61.43 & -1.84 \\
\hline 85.0 & \multirow[t]{3}{*}{ R50 } & 60.48 & & 85.0 & \multirow[t]{3}{*}{ R50 } & 62.24 & \\
\hline 82.5 & & 55.08 & \multirow{2}{*}{$\begin{array}{c}-8.93 \\
-13.87\end{array}$} & 82.5 & & 59.95 & -3.68 \\
\hline 80.0 & & 52.09 & & 80.0 & & 56.96 & -8.48 \\
\hline 85.0 & \multirow[t]{3}{*}{ R42 } & 57.16 & \multirow{3}{*}{$\begin{array}{l}-9.15 \\
-9.17 \\
\end{array}$} & 85.0 & \multirow[t]{3}{*}{ R42 } & 59.28 & \\
\hline 80.0 & & 51.93 & & 82.5 & & 55.22 & -6.85 \\
\hline 82.5 & & 51.92 & & 80.0 & & 55.21 & -6.87 \\
\hline 80.0 & \multirow[t]{2}{*}{$\mathrm{F}$} & 57.80 & \multirow[b]{2}{*}{-15.36} & 80.0 & \multirow[t]{2}{*}{$\mathrm{F}$} & 61.34 & \\
\hline 85.0 & & 48.92 & & 85.0 & & 60.34 & -1.63 \\
\hline 85.0 & \multirow[t]{3}{*}{ R42R5 } & 58.71 & \multirow{3}{*}{$\begin{array}{l}-1.81 \\
-5.67\end{array}$} & 85.0 & \multirow[t]{3}{*}{ R42R5 } & 60.86 & \\
\hline 82.5 & & 57.65 & & 80.0 & & 59.83 & -1.69 \\
\hline 80.0 & & 55.38 & & 82.5 & & 58.57 & -3.76 \\
\hline 85.0 & \multirow[t]{3}{*}{ R42R4 } & 58.74 & \multirow{3}{*}{$\begin{array}{l}-2.81 \\
-4.44\end{array}$} & 85.0 & \multirow[t]{3}{*}{ R42R4 } & 59.79 & \\
\hline 82.5 & & 57.09 & & 82.5 & & 59.76 & -0.05 \\
\hline 80.0 & & 56.13 & & 80.0 & & 60.15 & 0.60 \\
\hline 82.5 & \multirow[t]{3}{*}{ R42R3 } & 58.04 & \multirow{3}{*}{$\begin{array}{l}-0.28 \\
-1.93\end{array}$} & 82.5 & \multirow[t]{3}{*}{ R42R3 } & 61.56 & \\
\hline 85.0 & & 57.88 & & 80.0 & & 60.21 & -2.19 \\
\hline 80.0 & & 56.92 & & 85.0 & & 57.98 & -5.82 \\
\hline
\end{tabular}

Table 7. Load capacity of joints versus overlap length 
than that of the R42 type ends. The author expected that the samples rounded to a radius of 42 $\mathrm{mm}$ would have higher load capacities than those rounded to $50 \mathrm{~mm}$. These results show that there is potential in differentiating sample end radius finishing.

The samples with R42R3, R42R4 and R42R5 type ends have a similar failure force $\mathrm{F} 95 \%$ for every tested overlap length. The differences between the lowest and the highest values are $3.48 \%(80 \mathrm{~mm}), 1.83 \%(82.5 \mathrm{~mm})$ and $1.76 \%$ ( $85 \mathrm{~mm})$. The F95\% values of the samples with R42R3, R42R4 and R42R5 type ends are higher than those obtained for the normal type bond ends by $25.0-28.5 \%(80 \mathrm{~mm})$ and $3.8-5.5 \%(85 \mathrm{~mm})$.

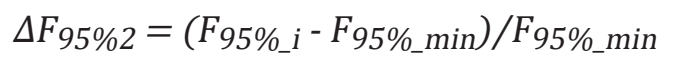

where: $\Delta \mathrm{F}_{95 \% 2}-$ difference in the load capacity [\%].

$$
\Delta F_{\text {Dav2 }}=\left(F_{\text {Dav } i}-F_{\text {Dav_min }}\right) / F_{\text {Dav_min }}
$$

where: $\Delta \mathrm{F}_{\text {Dav2 }}$ - difference in the mean load capacity.

Only one failure mode was observed in the study, i.e. overlap detachment on the steel-adhesive interface. It may indicate the correct preparation of the adhesive-bonded elements in terms of substrate preparation. In the samples chamfered along their thickness with adhesive outflow (type F), the failure started in the adhesive outflow and progressed to the steel-adhesive interface. This observation agrees with the author's previous research results [12].

\section{DISCUSSION OF RESULTS}

The results demonstrate that change in overlap length affects joint load capacity. Only in the case of the F-type end samples, a change in their overlap length resulted in reduced load capacity (15.7\%); this, however, could result from sample preparation or invisible material defects, as proved by the author's previous research results [12] and other results in this study. The $85 \mathrm{~mm}$ overlap length samples have a higher load capacity than the $80 \mathrm{~mm}$ overlap length samples, for the following end types: Z (26.5\%), R50 (16.1\%), R42 (10.1\%), R42R5 (6.0\%), R42R4 (4.6\%), R42R3 $(2.0 \%)$. These results show that, depending on the bond end type, increased overlap length has significant impact - type Z (26.5\%), or its significance is lower - type R42R3 (2.0\%). The results demonstrate that the effective bond length was practically achieved by the R42R3 type samples.

An analysis of the results obtained for the 80 $\mathrm{mm}$ overlap length samples presented in Table 8 provides two observations. First, the highest load

\begin{tabular}{|c|c|c|c|c|c|c|c|}
\hline Bond length [mm] & Sample type & $\mathrm{F}_{95 \%}[\mathrm{kN}]$ & $\mathrm{DF}_{95 \% 2}[\%]$ & Bond length [mm] & Sample type & $\mathrm{F}_{\mathrm{Dav}}[\mathrm{kN}]$ & $\mathrm{DF}_{\mathrm{Dav} 2}[\%]$ \\
\hline \multirow{7}{*}{80.0} & Z & 44.29 & 0.00 & \multirow{7}{*}{80.0} & $\mathrm{R} 42$ & 55.21 & 0.00 \\
\hline & $\mathrm{R} 42$ & 51.93 & 17.25 & & $\mathrm{R} 50$ & 56.96 & 3.17 \\
\hline & R50 & 52.09 & 17.61 & & R42R5 & 59.83 & 8.37 \\
\hline & R42R5 & 55.38 & 25.04 & & R42R4 & 60.15 & 8.95 \\
\hline & R42R4 & 56.13 & 26.73 & & R42R3 & 60.21 & 9.06 \\
\hline & R42R3 & 56.92 & 28.52 & & $\mathrm{~F}$ & 61.34 & 11.10 \\
\hline & $\mathrm{F}$ & 57.80 & 30.50 & & Z & 61.43 & 11.27 \\
\hline \multirow{6}{*}{82.5} & $\mathrm{R} 42$ & 51.92 & 0.00 & \multirow{6}{*}{82.5} & $\mathrm{R} 42$ & 55.22 & 0.00 \\
\hline & R50 & 55.08 & 6.09 & & R42R5 & 58.57 & 6.07 \\
\hline & R42R4 & 57.09 & 9.96 & & R42R4 & 59.76 & 8.22 \\
\hline & R50R3 & 57.57 & 10.88 & & R50 & 59.95 & 8.57 \\
\hline & R42R5 & 57.65 & 11.04 & & R50R3 & 60.01 & 8.67 \\
\hline & R42R3 & 58.04 & 11.79 & & R42R3 & 61.56 & 11.48 \\
\hline \multirow{7}{*}{85.0} & $\mathrm{~F}$ & 48.92 & 0.00 & \multirow{7}{*}{85.0} & $\mathrm{~F}$ & 56.44 & 0.00 \\
\hline & $z$ & 56.04 & 14.55 & & R42R3 & 57.98 & 2.73 \\
\hline & R42 & 57.16 & 16.84 & & R42 & 59.28 & 5.03 \\
\hline & R42R3 & 57.88 & 18.32 & & R42R4 & 59.79 & 5.94 \\
\hline & R42R5 & 58.71 & 20.01 & & Z & 60.46 & 7.12 \\
\hline & R42R4 & 58.74 & 20.07 & & R42R5 & 60.86 & 7.83 \\
\hline & R50 & 60.48 & 23.63 & & R50 & 62.24 & 10.28 \\
\hline
\end{tabular}

Table 8. Joint load capacity versus bond end shape 
capacity of the joint was achieved by the F-type samples, i.e. those with adhesive outflow and the tape chamfered at $45^{\circ}$. Second, the lowest loadbearing capacity was obtained for the samples with a normal strip end (Z-type samples). The values of F95\% for the R42 and R50 type samples with strip end rounding are $17.2 \%$ and $17.6 \%$ higher than the F95\% value obtained for the samples of type $Z$. Therefore, in this case, the rounding of the strip end increased the load capacity of the joint in relation to the normal end samples. The $\mathrm{F}_{95 \%}$ values of the samples with triple rounding of the strip end (R42R3, R42R4 and R42R5) are $25.0-28.5 \%$ higher than those of the Z-type samples and $6.3-6.6 \%$ higher than those of the samples with a single rounding of the strip end. The load capacity values of the samples R42R3, $\mathrm{R} 42 \mathrm{R} 4$ and R42R5 differ by $2.7 \%$. Therefore, it is difficult to determine the impact of corner radius on load capacity. The samples with triple rounding of the strip end have a slightly lower load capacity than the strongest F-type samples (1.5-4.4\%). The F-type samples achieved $30.5 \%$ higher load capacity compared to the samples with normal ends (type Z). These results agree with the author's previous results discussed in $[12,16,17]$ and with the results reported in $[11,13,15]$.

Regarding the samples with an overlap length of $82.5 \mathrm{~mm}$, the $\mathrm{Z}$ and F-type ends were not tested, but the R50R3-type end was introduced.

Two observations can be made when analysing the results of the $82.5 \mathrm{~mm}$ overlap length samples given in Table 8. First, the lowest load capacity of the joint was obtained for the samples of type R42. This observation is therefore compliant with other overlap length results. The R42 samples exhibit the lowest load capacity among the samples with rounded strip ends. Second, the load-bearing capacity is higher for the samples with triple-rounded strip ends (R42R3, R42R4, R42R5, R50R3) than for the samples of type R42 and R50. The triple rounding of the strip end increases load capacity of the joint in relation to one rounding by about $10.0-11.8 \%$ in relation to $\mathrm{R} 42$, and by about $4.8 \%$ for R50R3 in relation to R 50 . The load capacity values of the R42R3, R42R4 and R42R5 samples differ by $1.8 \%$.

An analysis of the results obtained for the 85 $\mathrm{mm}$ overlap length samples presented in the Table 8 reveals two things. First, the F-type samples have the lowest load capacity of the joint. This finding is completely inconsistent with the results reported in $[11,13,15]$ or with the author's previous research $[12,16,17]$. It may result from insufficient accuracy of composite strip chamfering. Second, the second lowest load-bearing capacity were obtained for the samples with a normal strip end (Z-type samples). Third, the highest load-bearing capacity was obtained for the R50type samples. These results differ with respect to the overlap length of $80 \mathrm{~mm}$, however there is some agreement. The values of $\mathrm{F}_{95 \%}$ for the samples with R42 and R50 type ends are $2.0 \%$ and $7.9 \%$ higher than those obtained for the Z-type samples. In this case, too, the triple rounding of the strip end leads to increased load capacity of the joint in relation to the normal end samples. The F95\% value of the samples with triple rounding of the strip end (R42R3, R42R4 and R42R5) is $3.3-4.8 \%$ higher than that obtained for the Ztype samples and $1.3-2.4 \%$ higher than that for the samples with a single rounding of the strip end (R42). For this case, the load capacity of the triple-rounded end samples is $2.9-4.5 \%$ lower than that of the R50-type samples. This is the only case where the R50 samples have a higher load capacity than the triple-rounded end samples. The load capacity values of the samples R42R3, $\mathrm{R} 42 \mathrm{R} 4$ and R42R 5 differ by $1.5 \%$, which is close to measurement error.

Finally, it should be emphasized that the findings of this study are limited to the analyzed ranges and types of parameters/materials. These findings may not be valid for other types of loading or composite material properties.

\section{CONCLUSIONS}

This study investigated the effect of bond end shape and overlap length on the load capacity of single lap adhesive joints of steel plate and carbon fibre-reinforced polymer (CFRP) under quasi-static loading. Preliminary experiments were carried out via laboratory testing of $60 \mathrm{CFRP} /$ steel samples with normal CFRP modulus and 20x1.4 mm CFRP sections with 8 types of bond end configurations. The following conclusions can be drawn:

1. The appropriate shape of the end of the FRP tape affects the load capacity of the joint. The study has shown that by rounding the strip end, it is possible to achieve results similar to the thickness of chamfered joints with adhesive outflow.

2 . The behavior of the reinforcement of steel elements depends not only on the preparation of the adhesive-bonded surfaces, but also on the 
proper fabrication of the composite sample end. By suitable treatment of the strip end with smoothly cut surface without fraying, a higher load capacity of the joint can be achieved, which can thus prevent premature failure of the joint due to peel off.

3. It is proposed that the composite sample end be machined by chamfering with excess adhesive or that it should be triple rounded in the transverse direction to increase load-bearing capacity of the adhesive joint. This effect was investigated via laboratory testing where 8 configurations were considered. However, the machining of CFRP strips by milling in the transverse direction can be tedious and difficult to perform.

4. Increasing the overlap length from $80 \mathrm{~mm}$ to 85 $\mathrm{mm}$ has a mixed effect on increasing load capacity of the tested joints. The overlap length increase by $6.25 \%$ leads to an increase in the failure force of the joint (F95\%) by 26.5\%. 16.1\%. $10.1 \%$. $6.0 \%$. $4.6 \%$ and $2.0 \%$ for the samples types: Z, R50, R42, R42R5, R42R4 and R42R3, respectively. As for the samples with triple rounding of the strip end, it is possible to determine the approximate effective bond length. Further increase in overlap length would not significantly increase load capacity of the joint.

\section{Acknowledgments}

The author would like to thank Energopol S.A. for free access to and preparation of steel samples for testing and Kam_El Engineers for free milling of CFRP tapes. Laboratory tests were funded by the National Science Centre (Poland) under the grant "Miniatura 4", project no. DEC-2020/04/X/ST8/00580.

\section{REFERENCES}

1. Kowal M. \& Szala M. Diagnosis of the microstructural and mechanical properties of over century-old steel railway bridge components. Engineering Failure Analysis. 2020; 110(104447): 1-17.

2. Bień J. Mosty kolejowe - uszkodzenia, awarie, katastrofy. In: Proc. of XXIV Konferencja Naukowo-Technicznej Awarie budowlane, SzczecinMiędzyzdroje, Poland. 2009; 45-62.

3. Jara M. Strengthening and Retrofitting of Steel Bridges, Springer Nature Singapore Pte Ltd., t. 9, 2018.

4. Rudawska A., Pawlak P., Miturska I., Stančeková D., Chyra M. Comparative Analysis of Welded and
Adhesive Joints Strength Made of Acid-Resistant Stainless Steel Sheets. Advances in Science and Technology Research Journal. 2017; 11(4): 97-102.

5. Charles D. Application of Advanced Materials. A Case Study on Actual Bridge Performance. NSFREU; 2006.

6. Phares B.M., Wipf T.J., Abu-Hawash F.W.A., Lee Y.-S. Strengthening of Steel Girder Bridges Using FRP. Ames, Iowa, 2003.

7. Moy S.S.Y. FRP composites. Life extension and strengthening of metallic structures. ICE design and practice guides. Institution of Civil Engineers; 2001.

8. Harries K.A. FRP International - the official newsletter of the International Institute for FRP in Construction. 2001; 8(3).

9. Łagoda G., Łagoda M. Strengthening steel bridge across Vistula River in Poland. In: Proc. of the Sustainable Infrastructure Environment Friendly, Safe and Resource Efficient Bangkok, Thailand. 2009; 96.

10. Zhao X.L., Zhang L. State-of-the-art review on FRP strengthened steel structures. Engineering Structures. 2007; 29: 1808-1823.

11. Stratford T.J., Chen J.F. Designing for tapers and defects in FRP-strengthened metallic structures. In: Proc. of the International Symposium on Bond Behaviour of FRP in Structures (BBFS 2005), 2005.

12. Kowal M. Strengthening of steel construction elements with carbon composite strips (in Polish). Wydawnictwo Politechniki Lubelskiej, Lublin; 2016.

13. Linghoff D., Haghani R., Al-Emrani M. Carbonfibre composites for strengthening steel structures. Thin-Walled Structures. 2009; 47: 1048-1058.

14. Cadei J.M.C., Stratford T.J., Duckett W.G., Hollaway L.C. Strengthening metallic structures using externally bonded fibre-reinforced polymers. Construction Industry Research and Information Association. 2004; C595.

15. Lang T.P., Mallick P.K. Effect of spew geometry on stresses in single lap adhesive joints. International Journal of Adhesion \& Adhesives. 1998; 18: 167-17.

16. Kowal M., Łagoda M. Strengthening of steel structures with CFRP strips. Roads and Bridges - Drogi i Mosty. 2017; 16(2): 85-99.

17. Kowal M., Hypki M. Numerical analyses of adhesive-bonded joints in steel I-beams reinforced with CFRP strips. ITMWeb of Conferences. 2017; 15.

18. Belingardi G., Goglio L., Tarditi A. Investigating the effect of spew and chamfer size on the stresses in metal/plastics adhesive joints. International Journal of Adhesion \& Adhesives. 2002; 22: 273-282.

19. Haghani R., Al-Emrani M., Kliger R. Interfacial stress analysis of geometrically modified adhesive joints in steel beams strengthened with FRP laminates. Construction and Building Materials. 2009;23:1413-1422. 
20. da Silva L.F.M., Lopes M.J.C.Q. Joint strength optimization by the mixed-adhesive technique. International Journal of Adhesion \& Adhesives. 2009;29:509-514.

21. Fitton M.D., Broughton J.G. Variable modulus adhesives: an approach to optimised joint performance. International Journal of Adhesion \& Adhesives. 2004;25:329-336.
22. da Silva L.F.M., Adams R.D. Techniques to reduce the peel stresses in adhesive joints with composites. International Journal of Adhesion \& Adhesives. 2007;27:227-235.

23. da Silva L.F.M., Adams R.D. Joint strength predictions for adhesive joints to be used over a wide temperature range. International Journal of Adhesion \& Adhesives. 2007;27:362-379. 